\title{
Endoscopic submucosal dissection of pancreatic heterotopia in children
}

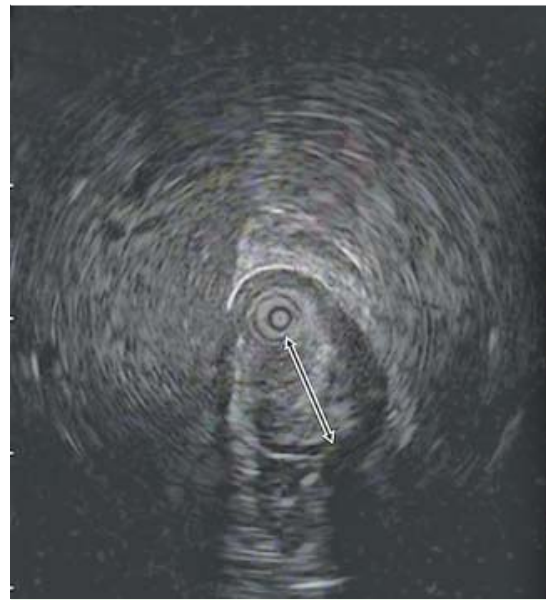

Fig. 1 Endoscopic ultrasound showing the extent of the submucosal lesion, which has a maximal diameter of $7.8 \mathrm{~mm}$ (arrow).

Aberrant pancreatic tissue is mostly found in the submucosal layer of the upper gastrointestinal tract, occurring in $1.7 \%$ of the population according to summarized post-mortem studies [1]. Gastric pancreatic heterotopia was first recognized by Klob in 1859 [2].

Herein we describe the resection of gastric pancreatic heterotopic lesions in children by endoscopic submucosal dissection (ESD). After the lesion has been localized endoscopically (GIF-HG 290; Olympus Medical, Tokyo, Japan), its extent within the stomach wall is clarified by ultrasound (UM-2R; Olympus Medical) ( $\bullet$ Fig. 1 ). A solution is circumferentially injected into the submucosa of the lesion ( $\bullet$ Fig. 2 ). This solution consists of $2.5 \mathrm{~mL} 1 \%$ sodium hyaluronate (Hyruan; LG Life Sciences) and $7.5 \mathrm{~mL}$ of a mixture that is made up of $5 \mathrm{~mL}$ adrenalin (1:10000; DBC Adrenaline Injection) and $1-2 \mathrm{~mL}$ of $8 \%$ indigo carmine (Indigocarmin Amino) diluted in $100 \mathrm{~mL}$ normal saline. An electrosurgical knife (DualKnife, KD-650L; Olympus Medical) is used for the mucosal incision and submucosal dissection of the lesion (O Fig.3).

A 12-year-old girl with known hemoglobin $\mathrm{H}$ disease presented with intermittent epigastric pain. She was diagnosed with gallstones and a polypoid lesion in the antrum of the stomach ( $\bullet$ Fig. 4). She underwent a laparoscopic cholecystectomy and the gastric lesion was removed by ESD

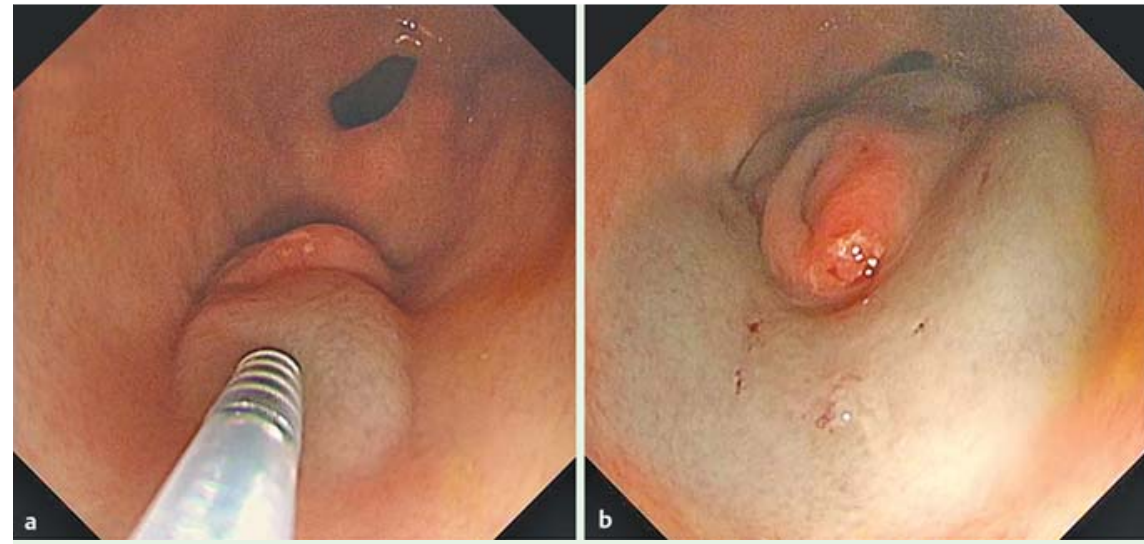

Fig.2 A solution of sodium hyaluronate, adrenalin, indigo carmine, and normal saline is circumferentially injected into the submucosa of the lesion: $\mathbf{a}$ the start of the injection; $\mathbf{b}$ completion of the injection.

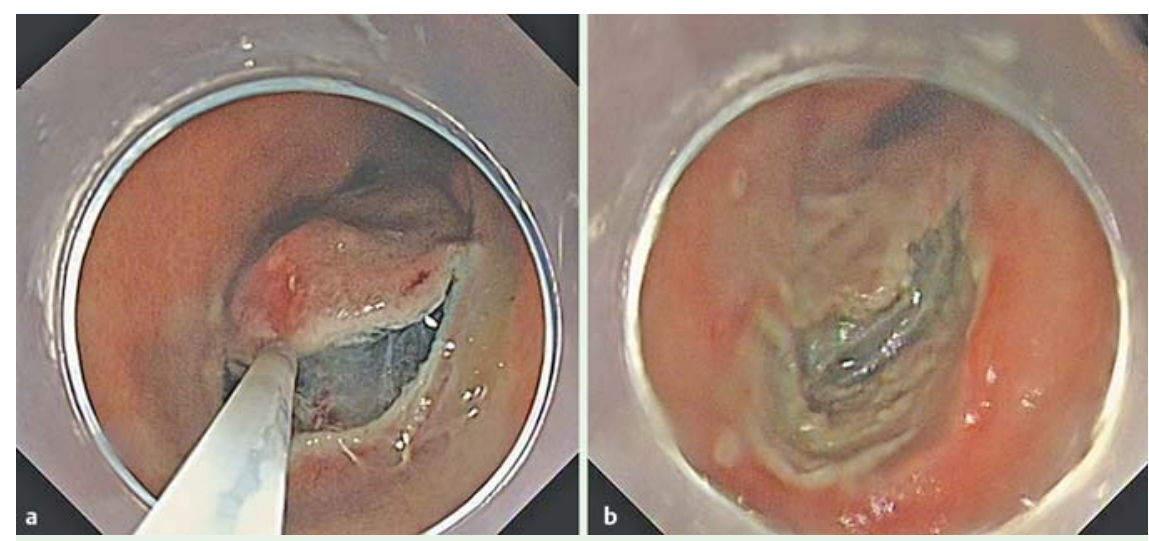

Fig. 3 View during endoscopic submucosal dissection showing: a the incision being made with an electrosurgical knife; $\mathbf{b}$ the antrum after completion of the resection.
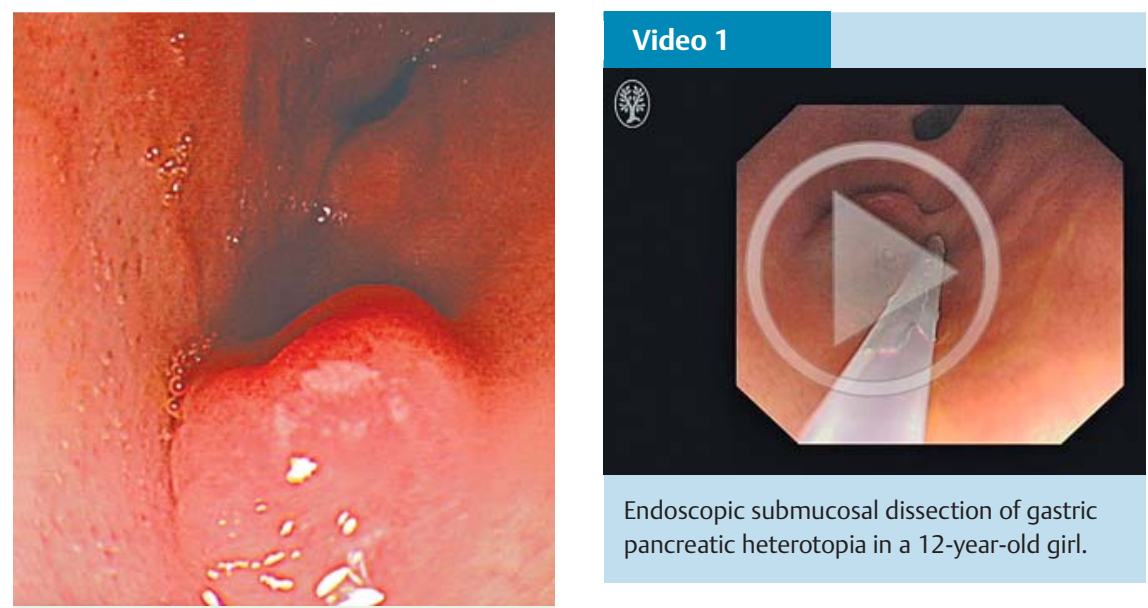

Endoscopic submucosal dissection of gastric pancreatic heterotopia in a 12-year-old girl.
Fig. 4 Endoscopic view of a polypoid tumor (pancreatic heterotopia) in the antrum with indentation. 
( Video 1; Fig. 3). At follow-up, she continued to complain of mild abdominal pain when eating oily foods.

Another antral lesion was identified in a 14 -year-old girl with epigastric pain. After the resection of her $10-\mathrm{mm}$ submucosal tumor by ESD, she returned with similar complaints at her follow-up.

The histology of both of these lesions showed pancreatic lobules with islet cells representing type 1 pancreatic heterotopia, according to the classification by von Heinrich [3]. Whilst the alleviation of symptoms is questionable in both patients, the timely removal of these lesions should prevent long-term risks such as gastric outlet obstruction through enlargement, blood loss through ulceration, and neoplastic transformation $[4,5]$. In both cases the ESD technique was performed without complications. There have been no late sequelae or evidence of local recurrence after a mean follow-up of 3 years.

ESD currently offers the most elegant method to resect aberrant pancreatic tissue, with perforation being the only significant risk factor [6].

Endoscopy_UCTN_Code_TTT_1AO_2AG

Competing interests: None
Yvonne Leung ${ }^{1}$, Christoph H. Houben ${ }^{1}$, Mabel Lacambra ${ }^{2}$, Anthony Teoh $^{3}$, Yuk Him Tam ${ }^{1}$, Philip Chiu ${ }^{3}$

${ }^{1}$ Division of Paediatric Surgery \& Paediatric Urology, Department of Surgery, Prince of Wales Hospital, Hong Kong, China

${ }^{2}$ Department of Anatomical and Cellular Pathology, Prince of Wales Hospital, Hong Kong, China

${ }^{3}$ Division of Upper GI Surgery, Department of Surgery, Prince of Wales Hospital, Hong Kong, China

\section{Acknowledgments \\ $\nabla$}

We would like to thank Eason $\mathrm{Ng}$ (IT Team, Department of Surgery) for his support editing the images and the video.

\section{References}

1 De Castro Barbosa JJ, Dockerty MB, Waugh $J M$. Pancreatic heterotopia; review of the literature and report of 41 authenticated surgical cases, of which 25 were clinically significant. Surg Gynecol Obstet 1946; 82: 527-542

2 Klob J. Pancreas-Anomalien (Anomalies of the pancreas). Zschr Gesellsch Ärzte Wien 1859; 15: $732-734$
3 von Heinrich $H$. Ein Beitrag zur Histology des sogenannten akzessorischen Pancreas (A contribution to the histology of the accessory pancreas). Virchows Arch Path Anat 1909; 198: 392 - 401

4 Martinez NS, Morlock CG, Dockerty MB et al. Heterotopic tissue involving the stomach. Annals Surg 1958; 147: 1-12

5 Fukumori D, Matsuhisa T, Taguchi $K$ et al. Ectopic gastric pancreatic cancer: report of a case. Hepatogastroenterology 2011; 58: $740-744$

6 Zhong Y-S, Shi Q Yao L-Q et al. Endoscopic mucosal resection/endoscopic submucosal dissection for gastric heterotopic pancreas. Turk J Gastroenterol 2013; 24: 322 - 329

\section{Bibliography}

Dol http://dx.doi.org/

10.1055/s-0042-119266

Endoscopy 2016; 48: E367-E368

(c) Georg Thieme Verlag KG

Stuttgart · New York

ISSN 0013-726X

\section{Corresponding author}

\section{H. Houben, MD}

Division of Paediatric Surgery Urology

Department of Surgery

Prince of Wales Hospital

The Chinese University of Hong Kong

Hong Kong SAR

China

Fax: +852-26324669

chhouben@web.de 